\title{
CONTEXTOS SOCIOPOLÍTICOS E HISTÓRICOS DA MULHER EM $A$ STREETCAR NAMED DESIRE, DE TENNESSEE WILLIAMS, A PARTIR DOS DILEMAS MORAIS DE KOHLBERG ${ }^{1}$
}

\section{WOMEN SOCIOPOLITICAL AND HISTORICAL CONTEXTS IN TENNESSEE WILLIAMS' A STREETCAR NAMED DESIRE FROM THE KOHLBERG'S MORAL DILEMMAS}

\author{
Luis Marcio Arnaut de Toledo \\ Universidade de São Paulo, São Paulo, São Paulo, Brasil \\ sp.vi@hotmail.com
}

\begin{abstract}
Resumo: Os estágios de desenvolvimento e dilemas morais propostos por Lawrence Kohlberg são utilizados como instrumento de análise dramatúrgica para identificar os contextos sociais, políticos e históricos da figuração da mulher na peça $A$ Streetcar Named Desire de Tennessee Williams. A partir destes estágios, procede-se a uma investigação para revelar o aprofundamento dos substratos ficcionais trabalhados pelo autor no que diz respeito à condição da mulher em sua obra, trazendo à tona como ela é lida e compreendida na sociedade. Evidencia-se, por fim, que a história da mulher é predominantemente atrelada aos valores patriarcais. Os Dilemas Morais propostos por Kohlberg, portanto, mostram-se instrumentos proficientes para a análise dramatúrgica, indo além da leitura hegemônica da obra do autor.
\end{abstract}

Palavras-chave: Tennessee Williams; A Streetcar Named Desire; Dramaturgia Norteamericana; Lawrence Kohlberg; Dilemas Morais

\begin{abstract}
The developmental stages and moral dilemmas proposed by Lawrence Kohlberg are used as an instrument of dramaturgical analysis to identify the social, political, and historical contexts of female figuration in Tennessee Williams' A Streetcar Named Desire. From these stages, an investigation is carried out to reveal the fictional substrata worked by the author relationned to woman in his work, bringing to the fore as it is read and understood in the society of his time. Finally, it is evident that the history of women is predominantly tied to patriarchal values. The moral dilemmas proposed by Kohlberg, therefore, prove to be proficient instruments to dramaturgical analysis and deepening of questions that go beyond the hegemonic reading of the work of the author.
\end{abstract}

Keywords: Tennessee Williams; A Streetcar Named Desire; American Dramaturgia; Lawrence Kohlberg; Moral Dilemmas.

\footnotetext{
${ }^{1}$ Este artigo foi apresentado na conclusão da disciplina da pós-graduação Ética, Educação e Aprendizagem Baseada em Problemas da Faculdade de Educação da Universidade de São Paulo (FE-USP) em 2018, ministrada pelo Prof. Dr. Ulisses Ferreira de Araújo e pelo professor visitante Dr. Jason M. Stephens da Universidade de Auckland, Nova Zelândia. Faz parte, portanto, da pesquisa do doutorado do autor deste artigo.
} 


\section{Kohlberg e os estágios de desenvolvimento moral}

As principais ideias sobre os estudos da moralidade e do desenvolvimento humano de Jean Piaget [1896-1980] foram seguidas por seu contemporâneo Lawrence Kohlberg [1927-1987], psicólogo e filósofo estadunidense, que redefiniu os estágios de julgamento moral proposto por seu mestre, concluindo que existem dessemelhanças quanto às regras de interpretação da vida e suas interações (FINI, 1991). Juntamente a Immanuel Kant [17241804], são três destacados pensadores nas pesquisas científicas e acadêmicas relacionadas à educação e ao desenvolvimento moral. Todavia, existem outras vertentes acadêmicas desta área aqui não cotejadas.

Originalmente, Piaget contemplou a análise de crianças em diversas idades, o que o levou a distinguir que existem diferenças em relação às regras e convenções em idades diferentes, determinando as seguintes fases (BIAGGIO, 2002, p. 20-21):

- anomia: as crianças não seguem as regras, embora compartilham o mesmo espaço;

- heteronomia: a criança percebe as regras como absolutas, porém de forma mística, fazendo o julgamento da ação como boa ou má sem base nas consequências dos atos, sem análise, sem considerar as intenções; e

- autonomia: a criança considera a finalidade e as consequências, acreditando nas regras como um consenso social, contudo podendo ser modificadas, se mutuamente consentido.

Expandindo esta pesquisa de Piaget, Kohlberg definiu dois estágios de desenvolvimento moral em cada um dos três níveis. Neles, os indivíduos são enquadrados com base no modo como respondiam às questões propostas a partir do debate de dilemas em relação aos julgamentos que fariam a respeito de um problema moral complexo, tal como o valor da vida humana ou os motivos para fazer coisas boas ou más. Seus estudos, com isso, estenderam os horizontes de entendimento sobre a moralidade, alargando os estágios de enquadramento dos membros de um grupo em determinadas normas, sua obediência, seus comprometimentos, manutenção e o nível moral desses valores compartilhados. "Ao invés de uma moralidade heterônoma para a moralidade autônoma, Kohlberg considerou que havia muitos estágios, portanto, a começar nos seis ou sete anos, estendendo-se até a idade adulta" (ESPÍNDOLA, s/d, p. 6).

Os dilemas apresentados por Kohlberg para as crianças responderem, no entanto, não tinham solução claramente correta ou incorreta (DE VRIES; ZAN, 1998), já que as respostas defendem ações por razões desiguais umas das outras, representando estágios de raciocínio irregulares. As questões são apresentadas e, a partir das respostas, é possível os diagnósticos sobre a maturidade e a situação moral dos entrevistados. Os níveis e estágios de desenvolvimento moral de Kohlberg são, portanto designados (KOHLBERG; LICKONA, 1990, p. 146-148; KOHLBERG, 1992, p. 5-9; BIAGGIO, 2002, p. 23-30):

- Nível I: Pré-convencional [de dois a aproximadamente seis anos]: onde a ação reprimida é má e a premiada é moralmente correta. Desta forma, a criança age para fugir do castigo ou para satisfazer os desejos individuais. Possui dois estágios:

- Estágio 1: punição e obediência;

- Estágio 2: hedonismo instrumental relativista.

- Nível II: Convencional [idade escolar]: o que é justo ou injusto se define pelo cumprimento às normas sociais e morais vigentes do seu grupo ou cultura. A inclinação é agir para satisfazer as convencionalidades e agradar. Possui dois estágios:

- Estágio 3: aprovação social e relações interpessoais;

- Estágio 4: lei e ordem para manter a moralidade.

- Nível III: Pós-convencional [adolescência]: o valor moral está sujeito aos princípios éticos universais. São mais dois estágios: 
- Estágio 5: contato social democrático;

- Estágio 6: princípios universais de consciência.

Por dilema moral considera-se o conceito apresentado por De Vries e Zan (1998, p. 98), que o caracteriza por ser uma situação na qual reinvenções, direitos ou pontos de vista conflitantes podem ser identificados. Os dilemas propostos por Kohlberg expunham os entrevistados a situações limites, o que remetia a reflexões, dúvidas, raciocínio e busca de solução de um caso de difícil decisão (BATAGLIA et al., 2000). De acordo com suas respostas, estes indivíduos são enquadrados em cada um dos estágios.

Adaptando este sistema de Kohlberg, elabora-se um plano para utilizá-lo como um instrumento particular para análise de conjuntura em obras artísticas, definidas aqui como a dramaturgia e sua análise. Isso é possível porque podem indicar um exame pormenorizado sobre dilemas e conflitos de uma determinada situação e a discussão sobre seu julgamento social, político e histórico. Evidencia-se, com isso, elementos reflexivos possíveis para uma compreensão dos substratos ficcionais, metáforas e abordagens críticas na dramaturgia. Obtêm-se, assim, respostas que aprofundam a compreensão dos elementos trabalhados pelo dramaturgo com a proposição de um dilema dado pelo próprio substrato ficcional da obra.

Por conseguinte, uma única questão poderá ter seis respostas correspondentes a cada um dos estágios, abrindo possibilidades para reflexão e compressão da obra. É de se notar que vários questionamentos podem ser feitos sobre um certo recorte, obtendo respostas múltiplas, muitas vezes contraditória. É exatamente essa dispersão no sentido dos vetores que faz emergir as nuances sobre a leitura do texto. Esta proposta, no entanto, não definirá um diagnóstico investigativo completo e definitivo, pois coteja apenas um recorte. Não será necessário propor os dilemas hipotéticos costumeiros às adaptações (STEPHENS, 2018). Eles serão concretos, reais, dados pela própria composição da obra, embora sejam direcionados para um objetivo específico: a investigação da conjuntura histórica, política e social da mulher.

Desta maneira, é possível analisar os elementos que permeiam a figuração feminina a partir da percepção do real dilema de uma personagem de uma obra dramatúrgica de Tennessee Williams, o estado da situação e a identificação dos interesses sociais e políticos das outras personagens que se relacionam com ela.

\section{Os dilemas de Kohlberg adaptados para a análise dramatúrgica}

Um dos dramaturgos mais aclamados dos teatros moderno e contemporâneo, conhecido no Brasil, mais principalmente, por conta de apenas 11 peças longas escritas em sua fase mais celebrada, entre 1945 e 1961, Tennessee Williams [1911-1983] tem sua proficuidade estabelecida na poesia, ensaios, artigos, novelas, contos, roteiros e na dramaturgia.

A leitura hegemônica de suas peças celebradas estabeleceu protocolos que impedem o alargamento dos expedientes tratados em sua constituição literária e teatral, levando-o a ser compreendido apenas pelo viés do que se convencionou chamar no Brasil de realismo psicológico, assim como à associação com sua biografia. Desta maneira, evitam-se contornos críticos à sociedade, que leva em conta os contextos históricos em que sua dramaturgia foi composta e as estéticas pretendidas para figurar a forma e o conteúdo das peças.

A Streetcar Named Desire (WILLIAMS, 1947), traduzida no Brasil como Um Bonde Chamado Desejo, é apontada como uma obra clássica do drama moderno estadunidense, fartamente montada no circuito comercial e encenações acadêmicas no Brasil e em diversas partes do mundo. A protagonista Blanche é uma referência no teatro e na dramaturgia, assim como em suas diversas adaptações fílmicas. É imersa em uma complexa rede intrincada de dilemas e conflitos, considerada a mais famosa de todas as personagens femininas de 
Williams - talvez, até, uma das que mais têm destaque no próprio drama estadunidense. A composição desta personagem será investigada por ser o trabalho mais encenado de Williams, mas, principalmente, por ser uma peça obstruída pela leitura hegemônica, que impede a compreensão de suas extensões sociais e políticas em relação à mulher. Mesmo que abarcada apenas por um recorte, será analisada neste trabalho de forma mais ampla e objetiva, desprendida das questões psicanalíticas tradicionais.

Utilizada em diversos contextos e adaptada para as diversas áreas de atuação (STEPHENS, 2016; 2017; 2018), a proposta de Kohlberg será, portanto, amoldada como metodologia auxiliar de estudo desta obra de Williams, no intuito de destacar os elementos que compõe os substratos sobre a simbologia e representação ficcional, devido suas características epistemológicas que despertam a reflexão e a crítica (LIMA, 2014).

Com esta adaptação, é possível discutir a internação de Blanche em um sanatório, investigando possíveis conexões desta ação dramática com valores pré-estabelecidos para o papel da mulher na sociedade. Espera-se que, assim, despontem os substratos sociais, políticos ou históricos que abarcam a conjuntura da personagem e que figurem o retrato da mulher no início do Século 20, período em que a ação está situada. Desta forma, espera-se que os estágios de Kohlberg possam, potencialmente, revelarem-se instrumentos eficazes para auxiliar a análise dramatúrgica no que tange ao entendimento aprofundado da conjuntura da personagem.

\section{A Streetcar Named Desire: loucura, internação e o papel social da mulher}

A Streetcar..., escrita em 1946 e cujo título inicial foi Blanche's Chair in the Moon [A Cadeira de Blanche na Lua], é uma peça da fase celebrada de Williams [1944-1961], com a qual fez grande sucesso e certificou sua aclamação definitiva no mainstream. Costumeiramente, sua leitura faz associações psicanalíticas, destacando as pulsões sexuais das personagens quase que exclusivamente, reproduzindo a hegemonia em que está mergulhada sua compreensão e análise.

O glamour que existe em torno desta obra começou em 1947, quando A Streetcar... se tornou a terceira montagem de uma peça sua na Broadway, com Jessica Tandy e Marlon Brando, seguido de sua versão fílmica em 1950 com Vivian Leigh, ganhadora do Oscar pelo papel de Blanche Dubois. No Brasil, a primeira Blanche foi vivida por Henriette Morinau em 1948, dirigida por Ziembinsky e Jacy Campos. Na época, o título mais charmoso e comercial encontrado para a tradução comercial era Uma Rua Chamada Pecado. Mas, também, a personagem trouxe destaque e prêmios para atrizes Maria Fernanda [1962-1963], Eva Wilma [1974], Tereza Rachel [1985], Flavia Pucci [1997], Leona Cavalli [2002] e Maria Luiza Mendonça [2017-2018] (TENNESSEE..., 2018).

Há uma versão anterior do texto intitulada Interior: Panic (a One-act Play) [Interior: Pânico (uma Peça em Um Ato)] (WILLIAMS, 2012), uma peça em um ato escrita no mesmo ano e publicada apenas em 2007, cuja personagem principal era Gladys Shannon, e que viria depois a se tornar Blanche Dubois na versão longa. Stella e Jack Kiefaber se tornariam Stella e Stanley Kowalski. Seus sobrenomes seriam trocados do irlandês e alemão, respectivamente, para o francês e o polonês. Teve sua estreia no Tennesssee Williams/New Orleans Literary Festival em março de 2005 no espetáculo Tennessee in the Quarter [Tennessee no Bairro]. Até sua estreia e publicação, era, então, desconhecida.

A personagem Blanche, antes aristocrata, chega a um cortiço para morar com a irmã e o cunhado, após perder a propriedade que tinha numa região importante do Sul dos Estados Unidos. Trabalhou como professora, vindo a abusar de um aluno de 17 anos. Casou-se com um rapaz homossexual e, quando ela descobre, ele se suicida. Sem perspectivas, desmantelada moralmente, alcoólatra, tem casos com vários homens, o que levanta a evidência, inclusive, 
de prostituição. Exausta, mas mantendo sua postura aristocrática, refugia-se no decadente bairro Desejo de Nova Orleans à procura do apoio da irmã Stella e do cunhado Stanley Kowalski, querendo um teto onde possa se abrigar. Lá, envolve-se com o amigo do cunhado, Mitt, mas que a deixa ao descobrir seu passado. Kowalski, também, após isso, estupra a moça, não obstante a gravidez da esposa, o que leva a um desequilíbrio emocional mais caótico em Blanche. Assim, ela é removida para a internação em um sanatório.

Analisada hegemonicamente como uma mulher plena de pulsões sexuais que abusa de um aluno menor e flerta com o cunhado, Blanche sofre uma interpretação psicanalítica, levando em conta apenas o desejo sexual da personagem pareado com um trocadilho com o bairro Desejo de Nova Orleans, cujo bonde que toma no início da peça é nomeado. O que se observa, ao final da peça, é a acusação de louca e sua expressa interação. Além, do estupro. Por estes motivos, a peça é famosa por ser analisada apenas como um completo entendimento da alma feminina, raramente lida sob os vieses sociais, políticos ou históricos relativos à mulher. Fica, portanto, claro que a loucura e a internação observados no final da peça são figuras de linguagens utilizadas pelo autor como uma forma de ir além das membranas superficiais dos substratos ficcionais apresentados.

Atualmente, o movimento antimanicomial afirma que não é suficiente tratar o paciente com psiquiatras e que o isolamento e a internação em manicômios poderiam até mesmo agravar a condição dos pacientes. $\mathrm{O}$ que se propõe é a substituição do tratamento manicomial por atendimentos terapêuticos através de centros comunitários, centros de convivências, terapia ocupacional e tratamento ambulatorial, salvaguardando a individualidade e subjetividades, respeitando a diversidade comportamental e de conduta.

Para investigar os fundamentos essenciais que envolvem a internação de Blanche e pensar na questão da internação ou não, um questionamento será apresentado como um dilema moral e investigado a partir de um interrogatório fundamentado em cada estágio proposto por Kohlberg, discutindo sua orientação moral, a justificativa da argumentação e a perspectiva sociomoral de cada estágio (KOHLBERG, 1992, p. 5-9).

Esta discussão não levará a uma solução estanque das questões, mas poderá fornecer entendimento das ambiguidades e contradições utilizadas. Mesmo porque a peça oferece muitas questões importantes a serem investigadas. A loucura é apenas um pequeno recorte analítico, a peça possui diversas questões a serem lidas além. Diante disso, o dilema moral proposto para analisar Blanche são os substratos morais e éticos que levam à imposição manicomial: afinal, o que esta internação figura?

\section{A figuração da mulher}

A figuração da mulher em $A$ Streetcar... é analisada a partir da personagem Blanche e fundada nas discussões de dilemas morais propostos em Kohlberg (1992, p. 10-11) e Biaggio (2002, p. 30-34), com as seguintes propostas de reflexões acerca do questionamento moral proposto: sexuais.

Proposição 1: Blanche deve ser internada para ser punida por ter cedido às pulsões

A identificação é com o Estágio 1 do Nível I - Pré-convencional, onde a internação pode ser compreendida como uma orientação moral para a punição e obediência feminina, uma ordem para ser recatada, serviçal e assexuada, um verdadeiro mandamento da mulher que deve seguir os protocolos sociais. A justificativa dos julgamentos morais é que Blanche deveria ter evitado suas pulsões sexuais, seu flerte com Kowalski, para impedir suas consequências - o estupro. A mulher precisa ser recatada e obscurecer seus desejos e vontades. A culpabilidade sobre seu infortúnio é, portanto, apenas dela por ter sido fraca perante aos ditames sociais impostos, sendo, também, responsável por evitá-lo. Cedendo aos impulsos, seria a única responsável, além de tudo, pelo ato do cunhado, já que o homem é 
eleito socialmente como soberano e a ele tudo é permitido para manter a ordem social e sua masculinidade. A perspectiva sociomoral é a subserviência de Blanche como panorama comportamental.

Proposição 2: Blanche deve ser internada para se tratar e não atrapalhar a vida da irmã com o cunhado.

Aqui há uma ideia de que a internação é uma opção à valorização da vida de Blanche, da união da irmã e do cunhado que a hospedam, supervalorizando a instituição do casamento, sem levar em consideração a eficácia do tratamento ou da certeza de que o casal será feliz. Há uma crença cega na medicina psiquiátrica e que a personagem supostamente louca é um peso que atrapalha a relação do casal. Não há uma reflexão crítica, portanto, sobre as relações humanas e suas complexidades. Há uma concordância com Quinn (1973), que afirma que a mendacidade rege o sistema social estadunidense, em que chega a existir como instituição, tais como o casamento e a família, a medicina, o sistema judicial, as leis e as religiões. Podese dizer que este tipo de afirmação está associada ao Estágio 2 do Nível I proposto por Kohlberg, pois obedece à orientação moral proposta, fazendo uma deferência autocentrada no menor esforço, sem questionamento, com uma tendência a evitar aborrecimentos, simplificando e aceitando a situação dolorosa da mulher. Portanto, Blanche estaria lutando pela sua sanidade, se internada. Tendo a busca da cura mais importante do que a cura em si, como um movimento interno da personagem em se equiparar ao senso comum, de que qualquer pessoa que esteja doente precisa buscar a cura. É uma forma de enquadramento social e ocultamento de subjetividade da mulher. O casal ficaria feliz para cuidar do futuro bebê sem a presença incômoda e excêntrica da irmã mais velha de Stella. A justificativa dos julgamentos está centrada na necessidade e nos interesses somente de Stella e Kowalski. Na perspectiva sociomoral, o que se encontra é apenas o ponto de vista dos interessados: Blanche deve ser tratada/internada e o casal deve se ver livre do peso da presença da solteirona. A orientação moral é calculista e instrumental.

Proposição 3: Blanche deve ser internada para ser curada.

Pode ser enquadrado no Estágio 3 do Nível II - Convencional. A orientação moral é que isso aconteça para que ela tenha aprovação social, afinal se ela se recuperar de sua loucura ela pode voltar às relações interpessoais, reconhecimento social e tornar a desempenhar o papel patriarcal reservado à mulher, restabelecendo a normalidade no que diz respeito aos estereótipos da mulher. Ela pode sair de sua condição de perdedora no contexto concorrente da relações capitalistas. Nos Estados Unidos há um profundo desprezo perante os que se dispersam ou não conseguem o sucesso, os chamados losers [perdedores]. Um termo ofensivo, pois desfoca o American dream da perspectiva de vida. Aqueles que são assolados com qualquer tipo de loucura são devidamente enquadrados neste panorama social de pessoas fracassadas, incapazes de vencer na sociedade estadunidense por estarem fora dos padrões sociais de normalidade. A justificativa dos argumentos é que Blanche precisa corresponder às expectativas alheiras e abrir mão de sua subjetividade. Há, portanto, uma necessidade em ser moralmente boa para seu grupo social, adequada ao papel que lhe foi atribuído de fêmea obediente para que se sinta e pareça boa e correta aos olhos daqueles que estão ao seu redor. Além de ter o corpo perfeito para ser usado pelos homens indistintamente e poder exercer as atividades serviçais do lar. A perspectiva sociomoral é de Blanche em relação à irmã, ao cunhado e ao Mitt, seu pretendente, pois são eles que a julgam, eles que concordam com sua internação.

Proposição 4: Blanche deve ser internada para ser afastada da sociedade, porque não é uma mulher que exerce seu papel social.

Está relacionado ao Estágio 4 do Nível II, porque Blanche é considerada anormal, fora da ordem, uma personagem que está à margem da sociedade, não é mais aristocrata, não está dentro dos meios de produção, um tipo de personagem desenraizada que caracteriza toda 
a obra de Tennessee. Embora ela queira parecer uma insider quando insistentemente procura agir ainda como uma pessoa nobre e com posses. O que se vê, no entanto, não é a sua vitimização. Ao contrário, essa estranha personagem, fora dos padrões do sistema, não pode ser um exemplo, uma referência ou um modus operandi de mudanças de estruturas, muito menos incitar o olho crítico ao establishment. O que se vê é uma personagem imersa em um processo destrutivo do status quo, apresentando uma deformação que a leva a ser vista quase que não humana, um tipo que foge da realidade padronizada e imposta como normal, uma desubjetivação da mulher, como aponta Savran (1993, p. 145). A mulher não pode agir com liberdade de escolha e atitudes. A figura de linguagem da loucura e sua internação é um elemento, portanto, expressionista na peça. A orientação moral é que a manutenção da ordem e do progresso social se estabeleça, portanto Blanche deve ser internada por ser uma personagem que está fora do grupo de estabelecidos sociais - é uma outsider. A justificativa deste argumento é que para manter o funcionamento das instituições da família e do casamento, principalmente, devem-se cumprir as obrigações sociais protocolizadas, afinal a sociedade corre risco do caos se todas as mulheres forem deslocadas como Blanche. A perspectiva sociomoral é a sociedade hierarquicamente superior, ditando suas normas e as mulheres obedecendo o patriarcado, submissas e silenciosas.

Proposição 5: Blanche não deve ser internada, ela precisa de convívio com pessoas que a ajudem a se manter íntegra.

A proposições 5 e 6 estão relacionadas ao Nível III - Pós-convencional por se tratarem de ações morais que não estão em conformidade às normas ou padrões sociais, mas a valores éticos universais, pareados com os ditames terapêuticos para casos semelhantes hoje na medicina psiquiátrica. A primeira é possível associar ao Estágio 5, cuja orientação moral é exatamente para o contato social. Blanche deverá se manter a todo custo na família para o relativismo das normas sociais e para a possibilidade de preservação de sua integridade feminina. A justificativa de argumentação é que o contato social pode proteger a mulher do agravamento de sua loucura. Cumprimento de protocolos pura e simplesmente não é útil, prejudicando sua condição, liberdade, seus direitos e sua relação com a irmã e os outros. A perspectiva sociomoral hierarquiza o panorama a partir de uma forma mais racional e de valorização universal das relações humanas e da instituição familiar: a irmã e o cunhado em último lugar.

Mitt.

Proposição 6: Blanche não deve ser internada, precisa ser aceita pelo seu pretendente,

Está relacionada com o Estágio 6, onde a personagem Blanche teria total liberdade para se relacionar com Mitt, que propõe a ela o casamento, podendo-se enquadrar, finalmente, na instituição familiar e encontrar um potencial de felicidade. Ela não precisa obedecer a ordem social e pode ser quem é, sem fingir ser aristocrata ou virginal. A orientação moral é para os princípios de escolha pessoal, desde que ela se realiza no namoro com Mitt, valorizando-se como mulher naquela relação. Seu passado como prostituta não é considerado, porque o homem a verá apenas como uma mulher no tempo presente. Talvez, nesta relação com Mitt, pela primeira vez, sentiu-se uma mulher como as outras, para ter uma vida convencional, sonho imposto para as mulheres como realização e felicidade. Como se todo o passado pudesse ser esquecido. A justificativa de argumentação é que esta decisão, embora de cunho romântico, é a mais racional, pois Blanche estaria comprometida com decisões de refazimento pessoal e reforma comportamental, mesmo que fosse contra seus desejos. A mulher estaria em par de igualdade de decisão, direitos e destino. A perspectiva sociomoral coordena um ponto de vista ideal ético, racional e universal: o casamento como solução de suas buscas interiores, satisfação sexual e valorização do seu papel de mulher como esposa. "Vemos, assim, que há uma relação entre comportamentos políticos e o julgamento moral" (BIAGGIO, 2002, p. 69). 


\section{Kohlberg e Tennessee Williams: uma possibilidade}

A partir da elaboração do dilema moral sobre a internação/loucura de Blanche, cada um dos seis estágios propostos por Kohlberg foram adaptados para a análise dramatúrgica com respostas distintas, levando a diferentes reflexões e possibilidades de leituras do texto. $\mathrm{O}$ exame detalhado de cada um dos itens esquadrinhados sob a orientação moral, justificativa de julgamento e perspectiva sociomoral de cada estágio revela um aprofundamento das elipses e dos substratos ficcionais trabalhados por Tennessee Williams. Em todos estes estágios há uma evidência de exposição social, política e histórica sobre o retrato da mulher na dramaturgia, revelando os protocolos, costumes e normas em que a sociedade emoldura a mulher no patriarcalismo. Sendo assim, o autor historiciza sua condição, trazendo à tona o tratamento a ela na sociedade de sua época, mesmo sem precisar analisar eventos históricos e seus contextos. A história da mulher é tão predominantemente atrelada aos valores patriarcais que por si só já evidencia questões importantes sobre sua realidade.

Portanto, a loucura e a internação de Blanche servem como uma metáfora para expor uma visão crítica acerca da sociedade. A internação está associada ao isolamento da mulher que foge dos padrões sociais, do papel construído pela sociedade patriarcal: submissa, silenciosa, obediente e serviçal. Mulheres que seguem suas pulsões sexuais, que são estupradas, solteiras, adúlteras, homossexuais, mães solteiras ou que oferecem algum comportamento de risco aos estereótipos, tal como Blanche, eram as escolhidas para o isolamento e internação, para o ofuscamento de sua ruptura, tida como acidental ou doentia. Eram as que deveriam ser afastadas do convívio social para evitar a desordem e a desobediência social. De acordo com Susan Sontag (2002, p. 91): "as doenças sempre foram usadas como metáforas para reforçar acusações de que uma sociedade era injusta ou corrupta." As figuras de imagens que fazem parte da doença são usadas para exprimir preocupação com a ordem social, já que a saúde é o que todos almejam para seu equilíbrio pessoal, familiar e de seu grupo social. E, justamente, é essa compreensão que se busca com esta investigação aqui proposta.

Tennessee vê a loucura como sinônimo de artificialidade, confinamento, castração, desertificação, destruição humana, silenciamento da mulher.

\footnotetext{
A dramaturgia de Williams retrata suas personagens às voltas com a loucura em uma combinação de honestidade brutal e ternura. [...] Às vezes, os loucos podem parecer superiores aos que os rodeiam, mas, frequentemente, são destruídos e 'desconsiderados.' As mulheres são, em especial, suscetíveis a esse destino [...] (O'CONNOR, 1997, p. 101-102, destaque da autora, tradução nossa). ${ }^{2}$
}

A abordagem apresentada desloca o enquadramento das personagens de Williams da sua abordagem tradicional psicanalítica centrada no indivíduo, para o foco sociológico, enaltecendo seu conhecimento meticuloso das realidades política e sociológica à sua volta. E esta proposta pode ser um passo muito adiante na direção de leituras alternativas do trabalho do dramaturgo no Brasil, encarando uma verdadeira releitura de $A$ Streetcar..., à contramão do convencionalismo nada crítico, certamente, retirando as balizas em torno de sua canonicidade literária e do padrão biográfico de interpretação que foi aplicado não só a esta peça e sua personagem feminina mais famosa, mas, igualmente, a todo conjunto de sua obra.

A partir da reflexão aqui exposta, é possível concordar com Ana Strnadová (2013, p. $8,10,11)$, que aponta um Tennessee Williams mais crítico que outros escritores, criando

\footnotetext{
2 "Williams's drama distinctively portray his mad characters with a combination of brutal honesty and tenderness. [...] Sometime nervous types may seem superior to those round them, but more often they are destroyed and 'put way'. Women are especially susceptible to such a fate [...]."
} 
personagens femininas menos virtuosas, mais conflituosas, embora, reprimidas e submissas. São admiradas e notáveis, certamente, por conta destas características paradoxais que a assemelha com mulheres reais, talvez um dos indícios pelos quais se associa a obra do dramaturgo com o realismo.

O chamado realismo poético não é portanto a única forma de se ler $A$ Streetcar... Esta associação certamente desvaloriza o simbolismo, portanto minimiza ou, até mesmo, negligencia a subjetividade expressionista do texto. As possibilidades de interpretações dos contextos trazidos por esta análise aqui apresentada confirma a estética do Expressionismo, já que ele funciona como uma radiografia que não se assemelha a um objeto, mas revela sua estrutura interior como uma fotografia não pode fazer (ROSENFELD, 1985). As figuras que envolvem Blanche refletem estruturas da vida interior da personagem da própria sociedade machista, imagens inconscientes não só das ilusões individuais, mas principalmente, do coletivo que as manifesta de modo patético. Certamente com esta leitura, produções que respondam melhor às estéticas contemporâneas e se adequem a esse público diferente da década de 1940, podem se aproximar mais das palavras do dramaturgo.

Blanche figura, portanto, uma visão crítica da mulher na sociedade, desmistificando a tradição das virtudes, beleza, passividade, virgindade e assexualidade, que contribuem para a instabilidade e desestruturação da sociedade moderna. Williams faz uma caricatura desta mulher vítima do patriarcalismo. Afinal, ela não conseguia se encaixar ou funcionar perfeitamente na normalidade, no mundo social (RIBKOFF; TYNDALL, 2011).

Blanche não tem escolha e nem voz. Ela é inapta a lutar pela sobrevivência. Suas características pessoais contradizem as condições objetivas e é por isso que não consegue ter sucesso em suas decisões subjetivas. Embora ela tente, de fato, ela não consegue se ajustar a um mundo em que as pessoas têm que ser populares, habilidosas, inteligentes, charmosas e destemidas para sobreviver, competir e satisfazer as expectativas sociais. Ela está fadada a viver fora da sociedade, não será classificada como normal. Deverá viver no mundo dos pobres, dos retardados mentais, dos abandonados, dos inaptos. Blanche tem uma grande identificação com o perfil do outsider, a pessoa desenraizada da sociedade e dos processos produtivos do capitalismo competitivo. Seu destino trágico deixa claro, com esta análise, uma remissão à crueldade artaudiana: os fracos devem ser derrotados ao invés de serem ajudados.

Desta forma, atesta-se que a utilização dos protocolos de Kohlberg é assertiva para esta análise dramatúrgica preconizada no recorte de $A$ Streetcar..., por atingir seus objetivos, não evidenciando resultados psicologizantes que remetem à leitura hegemônica das obras de Tennessee Williams, do chamado realismo psicológico, sem os contextos históricos, sociais e políticos.

\section{Referências}

Bataglia, P. U. R.; Morais, A.; Lepre, R. M. A “Teoria de Kohlberg sobre o Desenvolvimento do Raciocínio Moral e os Instrumentos de Avaliação de Juízo e Competência Moral em uso no Brasil". Estudos de Psicologia, [s.1], 15 (1), Jan-Abr, 2000, p. 25-32. Disponível em: $<$ http://www.scielo.br/pdf/epsic/v15n1/04.pdf>. Acesso: 13 set. 2018.

Biaggio, A. M. B. Lawrence Kohlberg - Ética e Educação Moral. São Paulo: Moderna, 2002.

De Vries, R; Kohlberg, L. Construtivist Early Education: Overview and Comparison with Other Program. Washington: Longman/NAEYC, 1990. 
De Vries, R.; Zan, B. A Ética na Educação Infantil: o Ambiente Sociomoral na Escola. Porto Alegre: Artes Médicas, 1998.

Espíndola, M. Z. B. L.; Lya, V. B. O Desenvolvimento Moral em Lawrence Kohlberg. s/d. Disponível em: < https://twiki.ufba.br/twiki/pub/LEG/WebArtigos/ >. Acesso: 12 set. 2018.

Fini, L. D. T. "Desenvolvimento Moral: de Piaget a Kohlberg". Perspectiva, 9 (16), jan-dez. Florianópolis, $\quad 1991, \quad$ p. $58-78 . \quad$ Disponível em: $<$ https://periodicos.ufsc.br/index.php/perspectiva /article/ >. Acesso: 12 set. 2018.

Kohlberg, L. La Democracia em la Escuela Secundaria - Educando para uma Escuela mas Justa. Tradução de Maria Mercedes Oraison. INCENE, Facultad de Humanidades, UNNE, 1992.

Kohlberg, L.; Lickona, T. Moral "Discussion and the Class Meeting". In: De Vries, R; Kohlberg, L. Construtivist Early Education: Overview and Comparison with Other Program. Washington: Longman/NAEYC, 1990, p. 143-181.

Lima, V. A. A. "De Piaget a Gilligan: Retrospectiva do Desenvolvimento Moral em Psicologia - um Caminho para o Estudo das Virtudes". Psicologia, Ciência e Profissão, [s.1], 24 (3), 2004, p. 12-23. Disponível em: <http://www.scielo.br/pdf/pcp/v24n3/ >. Acesso: 10 set. 2018.

O'Connor, J. Dramatizing Dementia: Madness in the Plays of Tennessee Williams. Texas: Bowling Green State University Popular Press, 1997.

Quinn, Margaret Lynne. "Mendacity" in Four Plays of Tennessee Williams: A Streetcar Named Desire, Cat on a Hot Tin Roof, Suddenly Last Summer, Small Craft Warnings. Dissertação (Masters in Fine Arts). McMaster University). McMaster University, Hamilton, 1973, 126 p. Disponível em: <https://macsphere.mcmaster.ca>. Acesso: 22 jun. 2017.

Ribkoff, F; Tyndall, F. "On the Dialectics of Trauma in Tennessee Williams' A Streetcar Named Desire". J Med Humanit, [s.1], No 32, vol 4, 2011, p. 325-337. Disponível em:

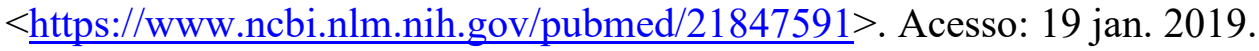

Rosenfeld, A. O Teatro Épico. São Paulo: Perspectiva, 1985.

Savran, D. Communists, Cowboys, and Queers - The Politics of Masculinity in the Work of Arthur Miller and Tennessee Williams. Minneapolis: University of Minnesota, 1992.

Sontag, S. A Doença como Metáfora. Tradução de Márcio Ramalho. Rio de Janeiro: Graal, 2002.

Stephens, J. M. "Bridging the Divide: the Role of Motivation and Self-regulation in Explaining the Judgment-action Gap Related to Academic Dishonesty". Frontiers in Psychology, [s.1], Vol. 9, Article 249, março, 2018, p. 1-15. Disponível em: $<$ https://www.frontiersin.org/articles/>. Acesso: 22 ago. 2018.

Stephens, J. M. "Creating Cultures of Integrity: a Multi-level Intervention Model for Promoting Academic Honesty". In: STEPHENS, J. M. Handbook of Academic Integrity. 2016, p. 1-10. Disponível em: <https://www.researchgate.net/publication/>. Acesso: 22 ago. 2018. 
Stephens, J. M. "How to Cheat and Not Feel Guilty: Cognitive Dissonance and Its Amelioration in the Domain of Academic Dishonesty". In: Stephens, J. M. Theory Into Pratice. 56:2. 2017, p. 111-120. Disponível em: <https://www.tandfonline.com/doi/pdf/>. Acesso: 22 ago. 2018.

Strnadová, A. Tennessee Williams's Southern Belles. Tese (Bacharelado em Língua Inglesa e Literatura)Faculdade de Artes da Masaryk University, 2013, 48 p. Disponível em:

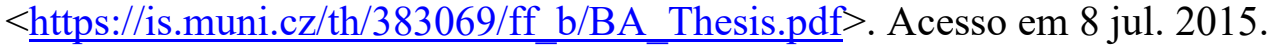

Tennessee Williams. Disponível em: Enciclopédia Itaú Cultural de Arte e Cultura Brasileiras. São Paulo: Itaú Cultural, 2018. Disponível em: $<$ http://enciclopedia.itaucultural.org.br/ pessoa360247/tennessee-williams $>$. Acesso: 08 Jan. 2018.

Williams, T. A Streetcar Named Desire. New York: New Directions, 1947.

Williams, T. "Interior: Panic (a One-Act Play)". In: Keith, T (ed). Tennessee Williams One Act Plays. Londres: Methuen Drama, 2012, p. 167-184.

Recebido em: 29 de agosto de 2019 Aceito em: 17 de novembro de 2019

Publicado em: Dezembro de 2019 